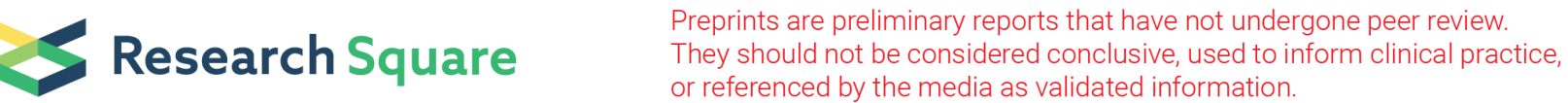

\section{Association of apolipoprotein C3 polymorphisms with non-alcoholic fatty liver disease: an updated meta- analysis}

\author{
Yu-Kang Chang \\ Tungs' Taichung MetroHarbor Hospital \\ Kuan-Chun Hsueh \\ Tungs' Taichung MetroHarbor Hospital \\ Chia-Hung Liu \\ Taipei Medical University \\ Yen-Li Lo \\ National Yang-Ming University \\ Yang-Sheng Lin \\ Mackay Memorial Hospital
}

Yuan-Hung Wang ( $\sim$ d508091002@tmu.edu.tw )

Taipei Medical University https://orcid.org/0000-0001-5570-2622

\section{Research}

Keywords: Apolipoprotein C3, Meta-analysis, Non-alcoholic fatty liver disease, Polymorphisms

Posted Date: August 27th, 2020

DOl: https://doi.org/10.21203/rs.3.rs-63439/v1

License: (c) (i) This work is licensed under a Creative Commons Attribution 4.0 International License. Read Full License 


\section{Abstract \\ Background}

The relationships between gene polymorphisms of apolipoprotein C3 (APOC3) and risk of non-alcoholic fatty liver disease (NAFLD) have been investigated, however, their findings were inconclusive. The aim of this meta-analysis is to evaluate the effects of APOC3 promoter region polymorphisms $(-455 \mathrm{~T} / \mathrm{C}$ and $-482 \mathrm{C} / \mathrm{T})$ on the susceptibility to NAFLD.

\section{Methods}

A comprehensive literature search was carried out with electronic databases including MEDLINE, EMBASE, Web of Science, and Google Scholar to identify eligible studies up to June 2019. Odds ratios (ORs) with 95\% confidence intervals (Cls) were calculated to assess the combined effect sizes. The level of heterogeneity, sensitivity, subgroup, and publication bias analyses were subsequently conducted.

\section{Results}

This meta-analysis included seven studies, containing 1,318 NAFLD cases and 1,691 controls fulfilling the inclusion and exclusion criteria. The pooled analysis showed significant associations between APOC3 -455T/C polymorphism and risk of NAFLD in allelic model $(\mathrm{OR}=1.33)$ and recessive model $(\mathrm{OR}=1.67)$, but not in the dominant model. When stratified by ethnicity, the polymorphism - 455T/C was found to be significantly associated with risk of NAFLD in the Caucasian population, but not in the Asian population. No association was evident between the polymorphism $482 \mathrm{C} / \mathrm{T}$ and risk of NAFLD.

\section{Conclusions}

Our findings suggest that APOC3 promoter region polymorphism - 455T/C may associate with risk of NAFLD in Caucasian population. Further studies with other functional polymorphisms are helpful to discover the effects of APOC3 gene on the development of NAFLD.

\section{Background}

Non-alcoholic fatty liver disease (NAFLD) is the most prevalent chronic liver disorder worldwide, affecting 25\% 30\% of the general population. ${ }^{1}$ It encompasses a wide spectrum of hepatic disorders ranging from simple steatosis to non-alcoholic steatohepatitis, which can progress to advanced liver fibrosis and ultimately cirrhosis and hepatocellular carcinoma. NAFLD is a multifactorial liver disorder and is also associated with insulin resistance, type 2 diabetes, obesity, metabolic syndrome, and cardiovascular disease. ${ }^{2,3}$ Racial and ethnic differences in the prevalence and clinical features suggest that both genetic and environmental factors may influence individual susceptibility to NAFLD. ${ }^{4}$

Although the pathogenesis of NAFLD is not fully understood, recent studies have focused on identifying NAFLDrelated genes, especially those candidate genes which are involved in lipid metabolism, insulin regulation, and obesity. A number of previous studies have evaluated the genetic influence of apolipoprotein C3 (APOC3) 
polymorphisms on the risk of NAFLD. ${ }^{5,6}$ APOC3 is synthesized primary in the liver and in minor quantities by the intestines, and is found in triglyceride-rich lipoprotein and high-density lipoprotein. ${ }^{7}$ APOC3 has a major role in adipogenesis by inhibiting lipoprotein-lipase activity and attenuating the hepatic uptake of triglyceride-rich particles. ${ }^{8}$ Those transgenic mice that overexpress human APOC3 were predisposed to NAFLD and insulin resistance, which provides one possible etiology for this common disorder in humans. ${ }^{9}$

The APOC3 gene is located on chromosome 11 q23 region. ${ }^{10}$ Single-nucleotide polymorphisms (SNPs) in the $A P O C 3$ gene have been extensively studied in relation to liver disorders. ${ }^{11}$ Among them, two polymorphisms (-455T/C and $482 \mathrm{C} / \mathrm{T}$ ) located in the insulin-response element of promoter region, are in linkage disequilibrium (LD) with the 3'untranslated region rs5128 polymorphism. ${ }^{12}$ In addition, these two SNPs that are in strong LD with each other have been reported to be associated with levels of triglyceride in plasma. ${ }^{13}$ Therefore, these two promoter region SNPs are regarded as functional genetic variants that contribute to elevated levels of APOC3 and triglyceride. Petersen et al. ${ }^{4}$ showed that these two polymorphisms $(-455 \mathrm{~T} / \mathrm{C}$ and $-482 \mathrm{C} / \mathrm{T})$ were associated with risk of NAFLD and insulin resistance in a cohort of Asian Indian men. Li et al. ${ }^{14}$ indicated that the APOC3 -455T/C variant involved in the development of NAFLD, insulin resistance, hypertension, hypertriglyceridemia, and low levels of HDL in the Chinese Han population.

A previous meta-analysis conducted by Zhang et al. ${ }^{15}$ reported no significant association between promoter polymorphisms of $A P O C 3$ and risk of NAFLD; however, those findings regarding the relationship between polymorphisms (-455T/C or -482C/T) of APOC3 and risk of NAFLD are still inconclusive. ${ }^{14,16-22}$ Therefore, we performed an updated meta-analysis to investigate the potential influence of APOC3 polymorphisms (-455T/C or $-482 \mathrm{C} / \mathrm{T}$ ) on individual susceptibility to NAFLD.

\section{Methods}

\section{Search strategy}

A literature search was conducted using the following electronic databases: MEDLINE, EMBASE, Web of Science, and Google Scholar without restriction of language. The databases were searched from their inception to June 2019. The search strategy for eligible studies included the following keywords or (and) (MeSH) terms: ("APOC3" or "apolipoprotein C3"), ("NAFLD” or "non-alcoholic fatty liver disease"), and ("SNP" or "single nucleotide polymorphism" or "polymorphism" or "mutation") in title or (and) abstract.

\section{Inclusion and exclusion criteria}

The inclusion criteria were as follows: (1) a case-control study evaluating the association between polymorphisms of APOC3 and risk of NAFLD; (2) the APOC3 -455T/C (rs2854116) and (or) -482C/T (rs2854117) promoter region polymorphisms were evaluated; (3) studies included healthy subjects as controls; and (4) there existed sufficient genotype data of cases and controls. If a study met criterion (1) but the original genotype data were not provided, or the study met criterion (2) but was a review, comment, or animal study, then those studies were finally excluded from the present meta-analysis.

\section{Data extraction}

Two independent authors ( $\mathrm{CH}$ Liu and JX Wu) extracted the data. Resolution of disagreement was achieved by a consensus and a senior author (YH Wang) will help to make a final decision. The following information was 
prospectively extracted: first author's name, publication year, country, ethnicity, number of cases and controls, genotype data of cases and controls, and genotyping method.

\section{Statistical analysis}

Testing for deviation of the genotype frequencies of each SNP in the controls from Hardy-Weinberg equilibrium (HWE) was carried out using a goodness-of-fit $\chi 2$ test. The strength of association between APOC3 genetic polymorphism and risk of NAFLD was calculated using odds ratio (OR) with $95 \%$ confidence interval (CI). Since the true underlying mode of inheritance of $A P O C 3$ alleles in NAFLD outcomes is unknown, OR estimates of APOC3 promoter region polymorphisms $(-455 \mathrm{~T} / \mathrm{C}$ or $-482 \mathrm{C} / \mathrm{T}$ ) were evaluated separately based on the allelic, dominant, and recessive genetic models.

Heterogeneity was evaluated by examining forest plots and statistically using Х2-based Cochran's Q test and Higgins' $\mathrm{I}^{2}$ heterogeneity index. Heterogeneity difference was regarded as statistically significant when Cochran's $Q$ statistic had $p<0.1$ or $\mathrm{I}^{2}>50 \%$. If there was statistical heterogeneity in studies, a random-effects model was applied to calculate a pooled OR. Otherwise, a fixed-effects model was applied. When there were concerns about heterogeneity, sensitivity analyses were performed by removing one study at a time to evaluate the impact of a single study. In addition, a subgroup analysis according to ethnicity and genotyping method were conducted to assess possible causes of heterogeneity. Publication bias was graphically evaluated by a funnel plot analysis. All $p$ values were twotailed. All analyses were done using RevMan 5.3 software which provided by the Cochrane Collaboration.

\section{Results}

According to the inclusion and exclusion criteria, 49 potentially relevant studies were identified initially through MEDLINE, EMBASE, Web of Science, and Google Scholar. After excluding those studies without providing original genotype data, a total of seven studies with 1,318 cases and 1,691 controls were finally included in the present metaanalysis (Fig. 1).

\section{Characteristics of eligible studies}

The main characteristics extracted from the seven included studies are shown in Table 1. All included studies were published between 2013 and 2018. The study populations were diverse, including Caucasian, Egyptian, Han Chinese, and Indian populations. Three studies ${ }^{14,22,23}$ performed a conventional polymerase chain reaction (PCR)-restriction fragment length polymorphism (RFLP) method for SNP genotyping, two studies ${ }^{17,21}$ used a conventional PCRsequencing method, and the others used real-time methods (TaqMan and MassARRAY) for SNP genotyping. The APOC3 promoter region polymorphisms (-455T/C and $-482 \mathrm{C} / \mathrm{T}$ ) are in strong LD with each other. Genotype distribution and allele frequencies of the included studies are shown in Table 2. Among them, Verrijken et al. ${ }^{19}$ assessed only one - 482C/T polymorphism. Therefore, six studies had an APOC3-455T/C polymorphism analysis, and three of those plus the study by Verrijken et al. ${ }^{19}$ had a $-482 \mathrm{C} / \mathrm{T}$ polymorphism assessment. As shown in Table 2, in five of seven studies, no deviation from HWE was detected in control population $(p>0.05)$. However, genotype distributions among controls in studies of Puppala et al. ${ }^{23}$ and Youssef et al. ${ }^{22}$ violated HWE. 
Table 1

Basic characteristics of studies included in the present meta-analysis

\begin{tabular}{|llllll|}
\hline First author & Year & Country & Ethnicity & $\begin{array}{l}\text { Sample size } \\
\text { (case/control) }\end{array}$ & Genotyping method \\
\hline Verrijken & 2013 & Belgium & Caucasian & $151 / 136$ & TaqMan SNP Genotyping Assays \\
\hline Li & 2014 & China & Han Chinese & $300 / 300$ & PCR-RFLP \\
\hline Niu & 2014 & China & Han Chinese & $390 / 409$ & PCR and sequencing \\
\hline Puppala & 2014 & India & Indian & $150 / 150$ & PCR-RFLP \\
\hline Song & 2017 & China & Han Chinese & $130 / 251$ & MassARRAY SNP Genotyping \\
\hline Yang & 2018 & China & Han Chinese & $97 / 362$ & PCR and sequencing \\
\hline Youssef & 2018 & Egypt & Egyptian & $100 / 83$ & PCR-RFLP \\
\hline Abbreviation: PCR, polymerase chain reactionrestriction; RFLP, fragment length polymorphism.
\end{tabular}

Table 2

Distribution of $A P O C 3$ gene promoter polymorphisms among included literatures

\begin{tabular}{|c|c|c|c|c|c|c|c|c|c|c|c|c|}
\hline \multirow{3}{*}{$\begin{array}{l}\text { First } \\
\text { author }\end{array}$} & \multirow[t]{3}{*}{ Year } & \multirow[t]{3}{*}{ Group } & \multicolumn{5}{|c|}{$-455 \mathrm{~T} / \mathrm{C}$} & \multicolumn{5}{|c|}{$-482 \mathrm{C} / \mathrm{T}$} \\
\hline & & & \multicolumn{3}{|c|}{ Genotype (n) } & \multirow{2}{*}{$\begin{array}{l}\text { Allele } \\
(\%)\end{array}$} & \multirow{2}{*}{$\begin{array}{l}\text { HWE } \\
\text { (p- } \\
\text { value) }\end{array}$} & \multicolumn{3}{|c|}{ Genotype (n) } & \multirow{2}{*}{$\begin{array}{l}\begin{array}{l}\text { Allele } \\
(\%)\end{array} \\
T\end{array}$} & \multirow{2}{*}{$\begin{array}{l}\text { HWE } \\
\text { (p- } \\
\text { value) }\end{array}$} \\
\hline & & & $\mathrm{T} / \mathrm{T}$ & $\mathrm{T} / \mathrm{C}$ & $\mathrm{C} / \mathrm{C}$ & & & $\mathrm{C} / \mathrm{C}$ & $\mathrm{C} / \mathrm{T}$ & $\mathrm{T} / \mathrm{T}$ & & \\
\hline \multirow[t]{2}{*}{ Verrijken } & 2013 & Cases & - & - & - & - & - & 88 & 52 & 11 & 24.5 & 0.40 \\
\hline & & Controls & - & - & - & - & - & 75 & 54 & 7 & 25.0 & 0.49 \\
\hline \multirow[t]{2}{*}{$\mathrm{Li}$} & 2014 & Cases & 94 & 131 & 75 & 46.8 & 0.03 & - & - & - & - & - \\
\hline & & Controls & 134 & 123 & 43 & 34.8 & 0.09 & - & - & - & - & - \\
\hline \multirow[t]{2}{*}{ Niu } & 2014 & Cases & 102 & 180 & 108 & 50.8 & 0.13 & 107 & 176 & 107 & 50.0 & 0.06 \\
\hline & & Controls & 104 & 195 & 110 & 50.7 & 0.35 & 104 & 203 & 102 & 49.8 & 0.88 \\
\hline \multirow[t]{2}{*}{ Puppala } & 2014 & Cases & 44 & 75 & 31 & 45.7 & 0.93 & 55 & 57 & 38 & 44.3 & 0.01 \\
\hline & & Controls & 60 & 81 & 9 & 33.0 & 0.01 & 62 & 46 & 42 & 43.3 & $<.001$ \\
\hline \multirow[t]{2}{*}{ Song } & 2017 & Cases & 44 & 63 & 23 & 41.9 & 0.96 & - & - & - & - & - \\
\hline & & Controls & 88 & 117 & 46 & 41.6 & 0.52 & - & - & - & - & - \\
\hline \multirow[t]{2}{*}{ Yang } & 2018 & Cases & 39 & 46 & 12 & 36.1 & 0.78 & - & - & - & - & - \\
\hline & & Controls & 135 & 177 & 50 & 38.3 & 0.51 & - & - & - & - & - \\
\hline \multirow[t]{2}{*}{ Youssef } & 2018 & Cases & 30 & 38 & 32 & 51.0 & 0.02 & 40 & 35 & 25 & 42.5 & 0.01 \\
\hline & & Controls & 40 & 35 & 8 & 30.7 & 0.93 & 34 & 30 & 19 & 41.0 & 0.02 \\
\hline
\end{tabular}




\section{Meta-analysis between APOC3 promoter region polymorphisms and NAFLD}

The main results between the gene polymorphism - 455T/C of APOC3 and risk of NAFLD are shown in Table 3. A random-effects model was applied to calculate a pooled OR of the $-455 \mathrm{~T} / \mathrm{C}$ polymorphism, for its heterogeneity was significant (Supplementary Table S1). The pooled analysis showed significant associations between APOC3 -455T/C polymorphism and risk of NAFLD in allelic model $(\mathrm{OR}=1.33,95 \% \mathrm{Cl}: 1.01 \sim 1.75, p=0.04)$ and recessive model $(\mathrm{OR}=$ 1.67, 95\% Cl: $1.02 \sim 2.71, p=0.04)$, but not in the dominant model (OR $=1.30,95 \% \mathrm{Cl}: 0.98 \sim 1.73, p=0.07)$ (Table 3 and Fig. 2).

Table 3

Meta-analysis of the association between APOC3 -455T/C polymorphisms and non-alcoholic fatty liver disease

\begin{tabular}{|c|c|c|c|c|c|c|c|}
\hline \multirow[t]{2}{*}{ Group/Subgroup } & \multirow[t]{2}{*}{$\begin{array}{l}\text { No. of } \\
\text { Studies }\end{array}$} & \multicolumn{2}{|l|}{$\begin{array}{l}\text { Allelic model } \\
\text { C vs. T }\end{array}$} & \multicolumn{2}{|c|}{$\begin{array}{l}\text { Dominant model } \\
\text { TC + CC vs. TT }\end{array}$} & \multicolumn{2}{|c|}{$\begin{array}{l}\text { Recessive model } \\
\text { CC vs. TC+ TT }\end{array}$} \\
\hline & & OR $(95 \% \mathrm{Cl})$ & $p$ & $\begin{array}{l}\text { OR }(95 \% \\
\mathrm{Cl})\end{array}$ & $p$ & $\begin{array}{l}\text { OR }(95 \% \\
\mathrm{Cl})\end{array}$ & $p$ \\
\hline Overall & 6 & $\begin{array}{l}1.33(1.01- \\
1.75)\end{array}$ & 0.04 & $\begin{array}{l}1.30(0.98- \\
1.73)\end{array}$ & 0.07 & $\begin{array}{l}1.67 \\
(1.02- \\
2.71)\end{array}$ & 0.04 \\
\hline \multicolumn{8}{|l|}{ Ethnicity } \\
\hline Asian & 5 & $\begin{array}{l}1.21(0.93- \\
1.57)\end{array}$ & 0.15 & $\begin{array}{l}1.21(0.91- \\
1.61)\end{array}$ & 0.19 & $\begin{array}{l}1.42 \\
(0.90- \\
2.26)\end{array}$ & 0.14 \\
\hline Caucasian & 1 & $\begin{array}{l}2.35(1.53- \\
3.61)\end{array}$ & $<.001$ & $\begin{array}{l}2.17(1.18- \\
3.98)\end{array}$ & 0.01 & $\begin{array}{l}4.41 \\
(1.90- \\
10.23)\end{array}$ & $<.001$ \\
\hline \multicolumn{8}{|l|}{$\begin{array}{l}\text { Genotyping } \\
\text { method }\end{array}$} \\
\hline PCR-RFLP & 3 & $\begin{array}{l}1.77(1.48- \\
2.11)\end{array}$ & $<.001$ & $\begin{array}{l}1.78(1.39- \\
2.29)\end{array}$ & $<.001$ & $\begin{array}{l}3.00 \\
(1.70- \\
5.28)\end{array}$ & $<.001$ \\
\hline $\begin{array}{l}\text { Real- } \\
\text { time/sequencing } \dagger\end{array}$ & 3 & $\begin{array}{l}0.99(0.85- \\
1.14)\end{array}$ & 0.84 & $\begin{array}{l}0.97(0.77- \\
1.21)\end{array}$ & 0.76 & $\begin{array}{l}1.00 \\
(0.78- \\
1.29)\end{array}$ & 1.00 \\
\hline
\end{tabular}

Heterogeneity differences were not significant among all analyses of the polymorphism - 482C/T. No association was evident between the polymorphism $-482 \mathrm{C} / \mathrm{T}$ and risk of NAFLD in allelic, dominant, or recessive models (Supplementary Tables S1, S2, and Figure S1).

In order to assess the potential influence of these study characteristics on the association between APOC3 promoter polymorphisms and risk of NAFLD, we performed subgroup analyses based on the characteristic of the studies. When stratified by ethnicity, associations between the polymorphism - 455T/C and risk of NAFLD were found to be significant in the Caucasian group (allelic OR: 2.35, 95\% Cl: 1.53 3.61, $p<0.001$; dominant OR: 2.17, $95 \%$ Cl: 1.18 3.98, $p=0.01$; recessive OR: 4.41, 95\% Cl: $1.90 \sim 10.23, p<0.001$ ), but not in the Asian group (Table 3). When 
stratified by genotyping method, associations between the polymorphism - 455T/C and risk of NAFLD were found to be significant in the PCR-RFLP group (allelic OR: 1.77, 95\% Cl: 1.48 2.11, $p<0.001$; dominant OR: 1.78, 95\% Cl: 1.39 $\sim 2.29, p<0.001$; recessive OR: 3.00, 95\% Cl: $1.70 \sim 5.28, p<0.001$ ) (Supplementary Table S1), but not in the realtime/sequencing group (Table 3 ). No significant association was found between polymorphism $-482 \mathrm{C} / \mathrm{T}$ and risk of NAFLD among all subgroup analyses (Supplementary Table S2).

\section{Sensitivity analysis and publication bias}

To appraise the stability of results, sensitivity analyses were carried out using the leave-one-out approach and recalculating the summary OR. Results showed that when Li et al.'s study ${ }^{14}$ was excluded, the statistical significance of the association between the $-455 T / C$ polymorphism and risk of NAFLD were lost in the allelic and recessive genetic models. This was also true when Puppala et al.'s study ${ }^{23}$ or Youssef et al.'s study ${ }^{22}$ was excluded (data not shown). The shapes of the funnel plots were symmetric, indicating the publication bias was low in the current metaanalysis ( $p$-value of Egger's test $>0.05)$.

\section{Discussion}

In the present study, we conducted an updated meta-analysis to evaluate the association between APOC3 polymorphisms (-455T/C or $-482 \mathrm{C} / \mathrm{T})$ and risk of NAFLD. The pooled results indicated that the APOC3 $-455 T / C$ polymorphism confers an increased risk for NAFLD under the allelic and recessive models of inheritance. In addition, a subgroup analysis showed statistically significant associations between the APOC3-455T/C polymorphism and risk of NAFLD in the Caucasian and PCR-RFLP groups, respectively.

The APOC3 -455T/C and - $482 \mathrm{C} / \mathrm{T}$ polymorphisms were thought to be related to increased risk of hypertriglyceridemia, metabolic syndrome, and coronary heart disease. ${ }^{24,25}$ Recently, these genetic variants were shown to be associated with the susceptibility to NAFLD. ${ }^{4}$ An in vitro promoter assay study demonstrated that these polymorphic sites at -455 and -482 , which fall within a previously identified insulin-response element, prevent insulin binding and thus increase APOC3 mRNA and protein levels. ${ }^{13}$ Insulin resistance is recognized as an essential pathophysiological factor of NAFLD, which results in hepatic de novo lipogenesis and a subsequent reduction in adipose tissue lipolysis, with a consequent increase in fatty acids in the liver. ${ }^{26}$ Taken together, it was proposed that that the variant alleles led to increased amounts of APOC3 and inhibition of lipoprotein lipase activity and triglyceride clearance, resulting in hypertriglyceridemia due to increased hepatic uptake of circulating chylomicron-remnant particles, and this results in NAFLD. 4,27

A meta-analysis conducted by Zhang et al. ${ }^{15}$ reported no association between APOC3 promoter polymorphisms and risk of NAFLD in different populations. These two SNPs are shown in strong LD with each other. It is noteworthy that Zhang et al. ${ }^{15}$ investigated a combined effect of both APOC3 polymorphisms by comparison with wild-type homozygotes $(-455 \mathrm{C} / \mathrm{C}$ and $-482 \mathrm{~T} / \mathrm{T})$ to carriers of one or more at-risk alleles (-455T and $-482 \mathrm{C})$, as Petersen et al.

${ }^{4}$ had previously done. Several studies evaluated the combined effect of APOC3 polymorphisms on NAFLD. However, the function of these two SNPs may be independent ${ }^{4}$. Furthermore, the effect of an individual SNP was not thoroughly demonstrated. In our updated meta-analysis, the pooled OR for these two SNPs related to the risk of NAFLD was estimated, in comparison to Zhang et al. ${ }^{15}$ Here, we found that one of the gene polymorphisms - 455T/C was weakly correlated with NAFLD $(p=0.041)$. On the other hand, the $-482 \mathrm{C} / \mathrm{T}$ polymorphism showed no detectable effect on NAFLD. Also of note is that Zhang et al. ${ }^{15}$ did not include very recent studies ${ }^{14,20-23}$ in their analysis. Thus, the present study provided a more comprehensive estimation of the association between APOC3-455T/C 
polymorphism and risk of NAFLD. The -455 site falls within a previously identified promoter insulin-response element. Lee et al. ${ }^{13}$ have demonstrated that the variant sequence at the -455 site reduces affinity for transcription factors that mediate the insulin response and provides a potential explanation for the inability of the variant promoter allele to respond to insulin. Insulin resistance results in increased delivery of free fatty acids to the liver. Also, insulin resistance is often accompanied by a state of chronic low-grade inflammation. Therefore, the ectopic lipid accumulation and activated inflammation cascades increases susceptibility to hepatic injury, and finally resulting in NAFLD. ${ }^{26}$

PCR-RFLP is a conventional SNP detection method. Among seven included studies in the current meta-analysis, three studies ${ }^{14,22,23}$ used this method for SNP genotyping. As shown in Table 2, in two of these three studies, ${ }^{22,23}$ genotype distributions in the control population violated HWE. Furthermore, a sensitivity analysis showed that statistical significance of $-455 \mathrm{~T} / \mathrm{C}$ was lost if one of these three studies ${ }^{14,22,23}$ was excluded. Heterogeneity differences were significant among the studies which assessed $-455 \mathrm{~T} / \mathrm{C}$ polymorphism in this meta-analysis. This suggests that various genotyping methods may lie behind the association between the APOC3-455T/C polymorphism and risk of NAFLD. Then we performed subgroup analyses and found significant results in the PCRRFLP group, but not in the other real-time/sequencing group (Table 3). Meanwhile, heterogeneity differences decreased and were not significant in either subgroup (see Supplementary Table S1). These findings indicate that the conventional PCR-RFLP SNP detection method introduced some heterogeneity differences.

NAFLD is a major public health hazard globally. Prevalence of NAFLD varied greatly by ethnicity, with the highest prevalence in Hispanics (45\%-58\%), followed by Caucasians (33\% 44\%), and lowest prevalence in African Americans (24\% 35\%). ${ }^{28,29}$ Therefore, we performed subgroup analyses based on the ethnicity of study subjects and found the - 455C allele had a significant effect on the risk of NAFLD in Caucasian subjects, but not in Asian subjects. Different genetic backgrounds and environments may contribute to the ethnic disparities in NAFLD.

Several limitations should be noted when interpreting results of our study. First, this meta-analysis included a limited number of studies. Meanwhile, most of the subjects were from Asian populations. Therefore, the generalizability of our findings is not certain, especially for Caucasian populations. Second, there was heterogeneity in the methods of NAFLD diagnosis; two studies ${ }^{19,21}$ used liver histology and the others used ultrasound. Furthermore, other factors such as age, gender, and ethnicity may also introduce significant between-study heterogeneity. Third, we were unable to adjust for potential confounding factors, which might have affected the accuracy in evaluating effects of APOC3 polymorphisms on the susceptibility to NAFLD.

\section{Conclusions}

In conclusion, our findings suggest that $A P O C 3$-455T/C promoter region polymorphism may influence individual susceptibility to NAFLD, especially for the Caucasian population. Further studies with other functional polymorphisms are helpful to evaluate the gene-gene interactions and the association between APOC 3 gene and the development of NAFLD.

\section{Abbreviations}




\begin{tabular}{|ll|}
\hline Abbreviations & Full form \\
\hline Apolipoprotein C3 & APOC3 \\
\hline Confidence interval & $\mathrm{Cl}$ \\
\hline Hardy-Weinberg equilibrium & HWE \\
\hline Non-alcoholic fatty liver disease & NAFLD \\
\hline Odds ratio & OR \\
\hline Polymerase chain reaction & PCR \\
\hline Restriction fragment length polymorphism & RFLP \\
\hline Single-nucleotide polymorphism & SNP \\
\hline
\end{tabular}

\section{Declarations}

\section{Ethics approval and consent to participate}

The present study is a meta-analysis for examining the effect sizes reported in previously published literatures. Therefore, this study was exempt from the Institutional Review Board (IRB) review.

\section{Consent for publication}

All participants signed informed consent.

\section{Availability of data and materials}

The present study is a meta-analysis for examining the effect sizes reported in previously published literatures.

\section{Competing interests}

The authors declare no conflict of interest.

\section{Funding}

Founding for this study was provided by grands from the Shuang Ho Hospital [grant number106TMU-SHH-25]; the Ministry of Science and Technology [grant number MOST 104-2314-B-038-079]; and the Taipei Medical University [grant number TMU103-AE1-B08], Taiwan. These funding sources had no role in the design, methods, subject recruitment, data collection, analysis, or preparation of this manuscript.

\section{Authors' contributions}

Concept - YHW; Design - YHW; Supervision - YHW; Materials - HTH, YLL; Data Collection and/or Processing - YSL ,YKC; Analysis and/or Interpretation -YKC , HTH, YLL; Literature Search - YSL, YLL; Writing Manuscript -YKC, YSL , HTH; Critical Review - YHW

\section{Acknowledgements}

Not applicable. 


\section{References}

1. Bellentani S. The epidemiology of non-alcoholic fatty liver disease. Liver Int. 2017;37(Suppl 1):81-4.

2. Rinella ME. Nonalcoholic fatty liver disease: a systematic review. JAMA. 2015;313(22):2263-73.

3. Hu J, Xu Y, He Z, et al. Increased risk of cerebrovascular accident related to non-alcoholic fatty liver disease: a meta-analysis. Oncotarget. 2018;9(2):2752-60.

4. Petersen KF, Dufour S, Hariri A, et al. Apolipoprotein C3 gene variants in nonalcoholic fatty liver disease. N Engl J Med. 2010;362(12):1082-9.

5. Jain V, Kumar A, Ahmad N, et al. Genetic polymorphisms associated with obesity and non-alcoholic fatty liver disease in Asian Indian adolescents. J Pediatr Endocrinol Metab. 2019;32(7):749-58.

6. Kumar A, Shalimar, Walia GK, Gupta V, Sachdeva MP. Genetics of nonalcoholic fatty liver disease in Asian populations. J Genet. 2019;98:29.

7. Bruns GA, Karathanasis SK, Breslow JL. Human apolipoprotein A-I-C-III gene complex is located on chromosome 11. Arteriosclerosis. 1984;4(2):97-102.

8. McConathy WJ, Gesquiere JC, Bass H, Tartar A, Fruchart JC, Wang CS. Inhibition of lipoprotein lipase activity by synthetic peptides of apolipoprotein C-III. J Lipid Res. 1992;33(7):995-1003.

9. Lee HY, Birkenfeld AL, Jornayvaz FR, et al. Apolipoprotein CIII overexpressing mice are predisposed to dietinduced hepatic steatosis and hepatic insulin resistance. Hepatology. 2011;54(5):1650-60.

10. Haddad IA, Ordovas JM, Fitzpatrick T, Karathanasis SK. Linkage, evolution, and expression of the rat apolipoprotein A-I, C-III, and A-IV genes. J Biol Chem. 1986;261(28):13268-77.

11. Talmud PJ, Humphries SE. Apolipoprotein C-III gene variation and dyslipidaemia. Curr Opin Lipidol. 1997;8(3):154-8.

12. Surguchov AP, Page GP, Smith L, Patsch W, Boerwinkle E. Polymorphic markers in apolipoprotein C-III gene flanking regions and hypertriglyceridemia. Arterioscler Thromb Vasc Biol. 1996;16(8):941-7.

13. Li WW, Dammerman MM, Smith JD, Metzger S, Breslow JL, Leff T. Common genetic variation in the promoter of the human apo CIII gene abolishes regulation by insulin and may contribute to hypertriglyceridemia. J Clin Invest. 1995;96(6):2601-5.

14. Li MR, Zhang SH, Chao K, et al. Apolipoprotein C3 (-455T > C) polymorphism confers susceptibility to nonalcoholic fatty liver disease in the Southern Han Chinese population. World J Gastroenterol. 2014;20(38):14010-7.

15. Zhang H, Chen L, Xin Y, Lou Y, Liu Y, Xuan S. Apolipoprotein c3 gene polymorphisms are not a risk factor for developing non-alcoholic Fatty liver disease: a meta-analysis. Hepat Mon. 2014;14(10):e23100.

16. Hyysalo J, Stojkovic I, Kotronen A, et al. Genetic variation in PNPLA3 but not APOC3 influences liver fat in nonalcoholic fatty liver disease. Journal of gastroenterology hepatology. 2012;27(5):951-6.

17. Niu TH, Jiang M, Xin YN, Jiang XJ, Lin ZH, Xuan SY. Lack of association between apolipoprotein C3 gene polymorphisms and risk of nonalcoholic fatty liver disease in a Chinese Han population. World J Gastroenterol. 2014;20(13):3655-62.

18. Valenti L, Nobili V, Al-Serri A, et al. The APOC3 T-455C and C-482T promoter region polymorphisms are not associated with the severity of liver damage independently of PNPLA3 I148M genotype in patients with nonalcoholic fatty liver. J Hepatol. 2011;55(6):1409-14.

19. Verrijken A, Beckers S, Francque S, et al. A gene variant of PNPLA3, but not of APOC3, is associated with histological parameters of NAFLD in an obese population. Obesity (Silver Spring Md). 2013;21(10):2138-45.

Page $10 / 13$ 
20. Song X, Song C, Fan L, et al. [Association of single nucleotide polymorphism of SIRT1 and APOC3 with nonalcoholic fatty liver disease]. Wei sheng yan jiu = Journal of hygiene research. 2017;46(4):527-32.

21. Yang $H$, Chen G, Song $C$, et al. A novel index including SNPs for the screening of nonalcoholic fatty liver disease among elder Chinese: A population-based study. Medicine. 2018;97(13):e0272.

22. Youssef MM, Elshaer A, Elbaz R, Ellazek YA, El-Waseef A, Settin A. ApolipoproteinC3 Gene Variants in Nonalcoholic Fatty Liver Disease in Egypt. American Journal of Biochemistry Molecular Biology. 2018;8(1):1622.

23. Puppala J, Bhrugumalla S, Kumar A, et al. Apolipoprotein C3 gene polymorphisms in Southern Indian patients with nonalcoholic fatty liver disease. Indian J Gastroenterol. 2014;33(6):524-9.

24. Lin B, Huang Y, Zhang M, Wang J, Wu Y. Association between apolipoprotein C3 Sst I, T-455C, C-482T and C1100T polymorphisms and risk of coronary heart disease. BMJ Open. 2014;4(1):e004156.

25. Miller M, Rhyne J, Chen $\mathrm{H}$, et al. APOC3 promoter polymorphisms C-482T and T-455C are associated with the metabolic syndrome. Arch Med Res. 2007;38(4):444-51.

26. Bugianesi E, Moscatiello S, Ciaravella MF, Marchesini G. Insulin resistance in nonalcoholic fatty liver disease. Curr Pharm Des. 2010;16(17):1941-51.

27. Ito Y, Azrolan N, O'Connell A, Walsh A, Breslow JL. Hypertriglyceridemia as a result of human apo ClII gene expression in transgenic mice. Science. 1990;249(4970):790-3.

28. Browning JD, Szczepaniak LS, Dobbins R, et al. Prevalence of hepatic steatosis in an urban population in the United States: impact of ethnicity. Hepatology. 2004;40(6):1387-95.

29. Williams CD, Stengel J, Asike MI, et al. Prevalence of nonalcoholic fatty liver disease and nonalcoholic steatohepatitis among a largely middle-aged population utilizing ultrasound and liver biopsy: a prospective study. Gastroenterology. 2011;140(1):124-31.

\section{Figures}




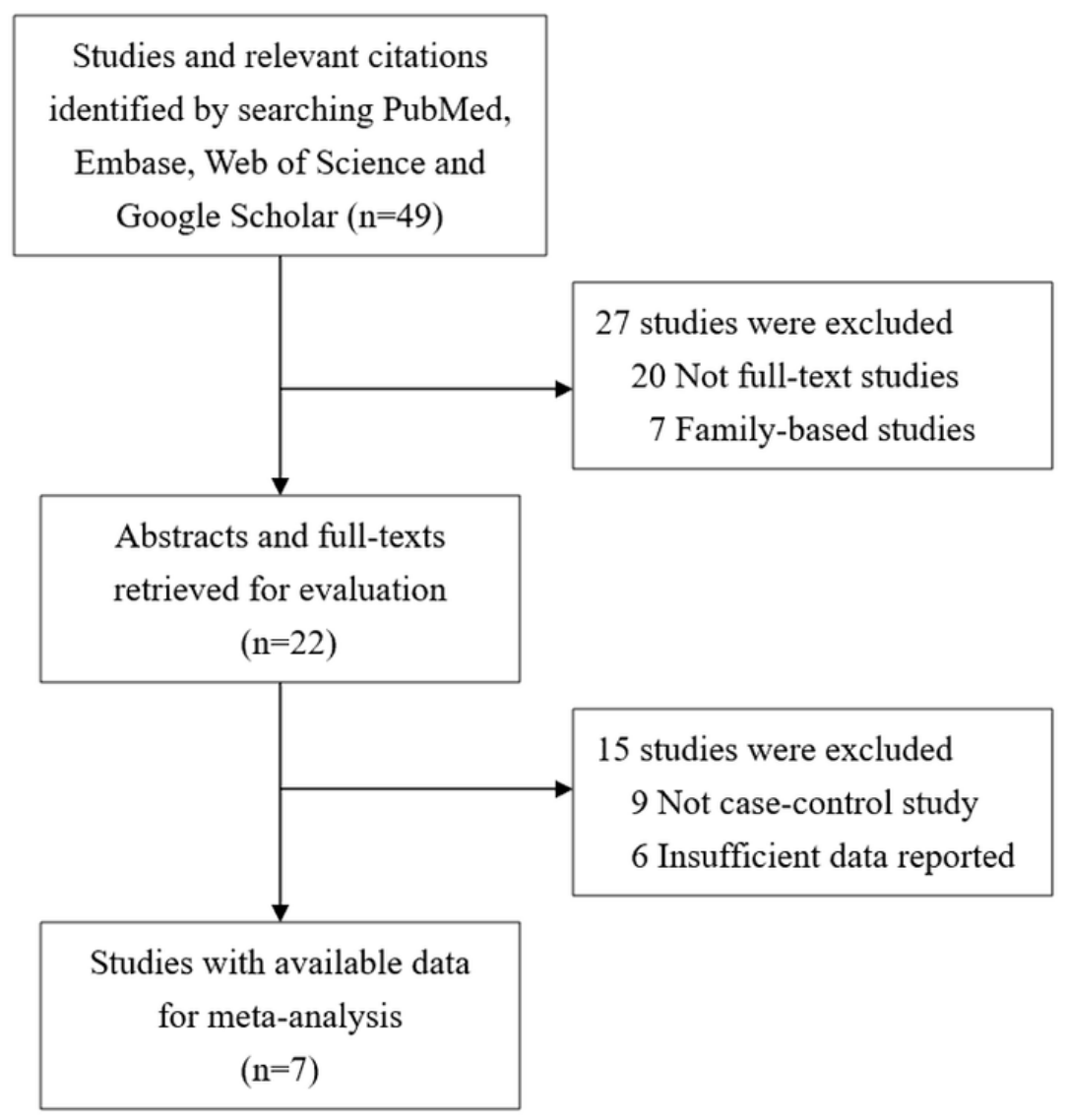

Figure 1. Flow diagram of the study selection.

Figure 1

Flow diagram of the study selection. 
(A) C vs. T

\begin{tabular}{|c|c|c|c|c|c|c|c|}
\hline Study or Subgroup & \multicolumn{2}{|c|}{ NAFLD } & \multicolumn{2}{|c|}{ Control } & \multicolumn{2}{|c|}{$\begin{array}{c}\text { Odds Ratio } \\
\text { Weight } \text { M-H. Random, } 95 \% \mathrm{Cl}\end{array}$} & $\begin{array}{c}\text { Odds Ratio } \\
\text { M.H. Random, } 95 \% \mathrm{Cl}\end{array}$ \\
\hline Li 2014 & 281 & 600 & 209 & 600 & $18.3 \%$ & $1.65[1.31,2.08]$ & \\
\hline Niu 2014 & 396 & 780 & 415 & 818 & $19.0 \%$ & $1.00[0.82,1.22]$ & \\
\hline Puppala 2014 & 137 & 300 & 99 & 300 & $16.1 \%$ & $1.71[1.23,2.38]$ & \\
\hline Song 2017 & 109 & 260 & 209 & 502 & $16.7 \%$ & $1.01[0.75,1.37]$ & \\
\hline Yang 2018 & 70 & 194 & 277 & 724 & $16.1 \%$ & $0.91[0.66,1.27]$ & \\
\hline Youssef 2018 & 102 & 200 & 51 & 166 & $13.8 \%$ & $2.35[1.53,3.61]$ & \\
\hline Total $(95 \% \mathrm{Cl})$ & & 2334 & & 3110 & $100.0 \%$ & $1.33[1.01,1.75]$ & \\
\hline Total events & 1095 & & 1260 & & & & \\
\hline $\begin{array}{l}\text { Heterogeneity. Tauz } \\
\text { Test for overall effect }\end{array}$ & $\begin{array}{l}0.09 ; C h i \\
z=2.02\end{array}$ & $\begin{array}{l}P^{2}=27.3 \\
P=0.04\end{array}$ & $6, d f=5$ & $(P<0$. & $.0001): I^{2}$ & $82 \%$ & $\begin{array}{lll}0.5 & 0.7 & 1\end{array}$ \\
\hline
\end{tabular}

(B) $\mathrm{TC}+\mathrm{CC}$ vs. TT

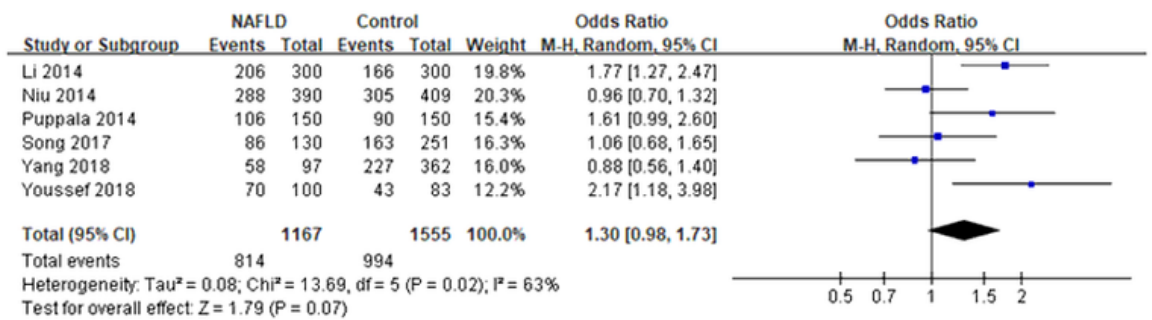

(C) $\mathrm{CC}$ vs. TC+TT

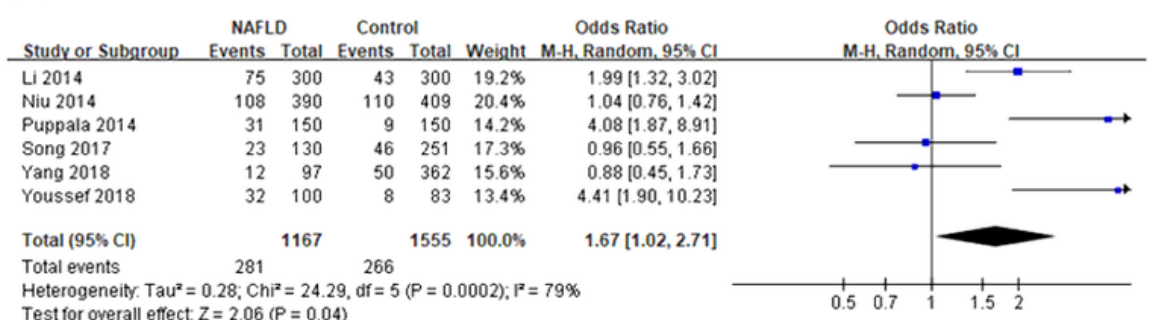

Figure 2. Forest plots for the association between $A P O C 3-455 \mathrm{~T} / \mathrm{C}$ and non-alcoholic fatty liver disease under the allelic (A), dominant (B), and recessive (C) genetic model.

Figure 2

Forest plots for the association between APOC3 -455T/C and non-alcoholic fatty liver disease under the (A) allelic (C vs. T), (B) dominant (TC+CC vs. TT), and (C) recessive (CC vs. TC+TT) genetic model.

\section{Supplementary Files}

This is a list of supplementary files associated with this preprint. Click to download.

- 6SUPPLEMENTARY.docx 